\title{
Use it and/or lose it-experience effects on brain remodeling across time after stroke
}

\author{
Rachel P. Allred ${ }^{1}$, Soo Young Kim ${ }^{2}$ and Theresa A. Jones ${ }^{1 *}$ \\ ${ }^{1}$ Department of Psychology and Institute for Neuroscience, University of Texas at Austin, Austin, TX, USA \\ ${ }^{2}$ Department of Integrative Biology, University of California Berkeley, Berkeley, CA, USA
}

\author{
Edited by: \\ Edward Taub, University of Alabama \\ at Birmingham, USA \\ Reviewed by: \\ Randolph J. Nudo, University of \\ Kansas Medical Center, USA \\ Christopher J. Steele, Max Planck \\ Institute for Human Cognitive and \\ Brain Sciences, Germany \\ *Correspondence: \\ Theresa A. Jones, Department of \\ Psychology and Institute for \\ Neuroscience, University of Texas at \\ Austin, 1 University Station A8000, \\ Austin, TX 78712, USA \\ e-mail: tj@austin.utexas.edu
}

The process of brain remodeling after stroke is time- and neural activity-dependent, and the latter makes it inherently sensitive to behavioral experiences. This generally supports targeting early dynamic periods of post-stroke neural remodeling with rehabilitative training (RT). However, the specific neural events that optimize RT effects are unclear and, as such, cannot be precisely targeted. Here we review evidence for, potential mechanisms of, and ongoing knowledge gaps surrounding time-sensitivities in RT efficacy, with a focus on findings from animal models of upper extremity RT. The reorganization of neural connectivity after stroke is a complex multiphasic process interacting with glial and vascular changes. Behavioral manipulations can impact numerous elements of this process to affect function. RT efficacy varies both with onset time and its timing relative to the development of compensatory strategies with the less-affected (nonparetic) hand. Earlier RT may not only capitalize on a dynamic period of brain remodeling but also counter a tendency for compensatory strategies to stamp-in suboptimal reorganization patterns. However, there is considerable variability across injuries and individuals in brain remodeling responses, and some early behavioral manipulations worsen function. The optimal timing of RT may remain unpredictable without clarification of the cellular events underlying time-sensitivities in its effects.

Keywords: upper extremity function, restorative plasticity, motor skill learning, learned non-use, motor cortex

\section{INTRODUCTION}

Stroke is a leading cause of chronic disability worldwide (Johnston et al., 2009). Upper extremity (hand and arm) impairments are especially prevalent lasting post-stroke disabilities (Lai et al., 2002; Kwakkel et al., 2003). Compensatory reliance on the nonparetic hand exacerbates impairments in the paretic side by encouraging its disuse (i.e., "learned nonuse," Taub et al., 2006). Motor rehabilitative training (RT) approaches are the main tools for treating these impairments, but they are typically insufficient to normalize function. A better understanding of the mechanisms of RT efficacy could help optimize its therapeutic potential.

Ischemic injury triggers prolonged periods of neuroanatomical reorganization (Li and Carmichael, 2006; Wieloch and Nikolich, 2006; Cheatwood et al., 2008). This reorganization unfolds over months or longer, but is particularly dynamic early after stroke (Anderson et al., 1986; Carmichael, 2006; Murphy and Corbett, 2009). There are likely to be windows of opportunity for driving functionally useful brain remodeling with RT, as well as windows of vulnerability for promoting suboptimal neural changes. When is early enough? When is it safe? What should be done in these windows? The answers to these questions remain unclear. Considerable variability in neural remodeling time courses can be expected between individuals and across brain regions (e.g., Hsu and Jones, 2006; Krakauer, 2007; Riley et al., 2011). Furthermore, earlier is not better for everything. Peri-infarct tissue is vulnerable to use-dependent excitotoxicity in very early periods (Humm et al., 1998) and there is potential to ingrain maladaptive behavioral strategies (Allred and Jones, 2008a,b; Jones and Jefferson, 2011).

Motor RT relies on mechanisms of skill learning, as does compensatory learning with the nonparetic hand. In intact brains, manual skill learning depends on practice-dependent synaptic structural and functional reorganization of motor cortex (Monfils et al., 2005; Kleim et al., 2006; Xu et al., 2009; Dayan and Cohen, 2011). These learning mechanisms are likely to interact with regenerative responses to stroke, many elements of which are sensitive to behavioral manipulations, as reviewed previously (Jones and Adkins, 2010). Optimally timing and tailoring RT requires a better understanding of how it interacts with post-stroke remodeling processes as they unfold over time. Below we review a framework for understanding these interactions, progress in unraveling them and ongoing knowledge gaps surrounding time-sensitivities for experience-driven plasticity after stroke.

\section{A DEVELOPMENTAL FRAMEWORK FOR UNDERSTANDING SENSITIVE TIME WINDOWS AFTER STROKE}

Greenough et al. (1987) introduced the term "experienceexpectant plasticity" to refer to the role of experience in brain development during early sensitive periods. The developing brain depends on external stimuli to shape neural circuitry patterns via mechanisms of synaptic competition, in which the most effectively activated neural connections are selectively maintained and matured, and those less well activated are eliminated (Black et al., 1997; Jones et al., 1998). A well-known example is the maturation 
of ocular dominance columns in visual cortex, which is driven by competitive activity of inputs from either eye. In the absence of visual stimulation of one eye, thalamocortical afferents of the remaining eye claim a disproportionate share of cortical territory, a pattern that is difficult to reverse (Hubel and Wiesel, 1965; Berardi et al., 2003; Wright and Bourke, 2013). This developmental process is contrasted with "experience-dependent" plasticity, i.e., the mechanism of learning. The two processes have overlapping cellular mechanisms, but vary in the magnitude and persistence of brain changes instigated by them (e.g., Zuo et al., 2005; Xu et al., 2009; Yu et al., 2013). In essence, experienceexpectant plasticity establishes the major connectivity patterns of the brain and experience-dependent plasticity continuously refines this connectivity across the lifespan.

Mechanisms of experience-dependent plasticity clearly contribute to post-stroke brain reorganization (Williams et al., 2006; Kerr et al., 2011) and to the efficacy of RT (Nudo, 2003; Adkins et al., 2006), and they should be able to do so at any time. An unresolved question is to what extent early neural remodeling events after stroke rely on experience-expectant mechanisms resembling those of brain development. The regenerative responses to stroke are highly sensitive to behavioral manipulations (Jones and Adkins, 2010). The early pro-growth environment is reminiscent of development (Cramer and Chopp, 2000; Carmichael, 2006; Murphy and Corbett, 2009) and some neural restructuring events resemble those typical of brain development (Jones and Jefferson, 2011). To the degree that these responses also behave in an experience-expectant manner, one would predict early periods after stroke in which it is not only (1) relatively easy to drive neural remodeling into functionally beneficial directions using manipulations of experience and neural activity, but also (2) easy for any experiences that dominate the time window to stamp in suboptimal or maladaptive circuitry patterns that are difficult to reverse.

The first prediction above is reasonably supported, though there are still knowledge gaps that hamper its usefulness for clinical decisions, as described below. The second prediction has received less attention, but its potential implications seem equally important (Jones et al., 2013). Even with early interventions, most of the experiences of stroke survivors occur outside of the treatment context (Bernhardt et al., 2004, 2007; West and Bernhardt, 2013), creating a potential for these experiences to dominate reorganizational patterns. The existence of experienceexpectant mechanisms after stroke would also raise the possibility of facilitating RT with treatments that prolong or reinstate these mechanisms (e.g., as demonstrated in visual system by Morishita and Hensch, 2008).

It is reasonable to draw upon brain development to understand brain reorganization after stroke, as cellular mechanisms for growing and re-growing neural connections overlap. However, unlike development, the adult post-stroke brain must remodel in a matrix of mature, dying, traumatized and dysfunctional structure. Stroke damages glia and vascular cells, as well as neurons, and substantially alters the intricate interactions among them. The creation of new stable patterns of neural connectivity after stroke depends on the coordinated plasticity of neurons, glia and vasculature.

\section{NEURAL, GLIAL, AND VASCULAR REMODELING: MOVING TARGETS FOR NEUROREHABILITATION}

The loss of neurons in the core of ischemic injury leaves connected regions partially denervated and efferent neurons stripped of postsynaptic targets. The counteroffensive is the induction of a growth permissive environment that promotes axonal sprouting, synaptogenesis and dendritic remodeling (Kelley and Steward, 1997; Carmichael, 2006; Brown et al., 2010). Synapse densities around an infarct decline and then recover over time to varying degrees depending on proximity to the infarct core (Brown et al., 2008; Sigler and Murphy, 2010). Remaining projections to denervated regions sprout collateral axons and form new synapses (Cotman and Anderson, 1988; McNeill et al., 2003; Dancause et al., 2005). The axons that most prominently contribute to reinnervation tend to be the most abundant (Raisman and Field, 1990) and the most active (in firing) of the surviving projections (Carmichael and Chesselet, 2002; Carmichael, 2003; Cesa and Strata, 2005; Brus-Ramer et al., 2007). The latter property helps make the remodeling processes sensitive to manipulations of neural activity (Brus-Ramer et al., 2007; Adkins et al., 2008; Carmel et al., 2010) and behavior (Jones and Jefferson, 2011; Overman et al., 2012). There are also persistent alterations in excitatory and inhibitory activity patterns that present potential targets for combining RT with other treatments (Carmichael, 2012; Zeiler et al., 2013).

Post-ischemic reactions of neurons, astrocytes and vasculature are tightly coordinated. For example, factors expressed by glia and neurons stimulate the formation of blood vessels, and new vessels release neural growth and survival factors (Wieloch and Nikolich, 2006; Hermann and Chopp, 2012). Glia have diverse roles in mediating neuroregenerative responses (Kelley and Steward, 1997; Mack and Wolburg, 2013). Astrocytes are intricately involved in synaptic plasticity (Murai et al., 2003; Haber et al., 2006; Eroglu and Barres, 2010). Astrocytes release thrombospondins to promote synapse formation (Christopherson et al., 2005; Eroglu et al., 2009), cholesterol to promote synapse maturation (Mauch et al., 2001; Goritz et al., 2005) and D-serine to regulate synaptic potentiation and depression (Panatier et al., 2006). Astrocytic behavior is neural activity- and experiencedependent (Jones and Greenough, 2002; Theodosis et al., 2008), e.g., astrocytic reactions to denervation in motor cortex are elevated by forced forelimb use (Bury et al., 2000). After cortical infarcts, quantities of perisynaptic astrocytes and synapses vary together with injury severity (Kim and Jones, 2010), and behavioral outcome is altered by pharmacological manipulation of astrocytic glutamate transport (Kim and Jones, 2013).

There are multiphasic vascular responses after stroke. Ischemic stroke results in expanses of reduced cerebral blood flow (CBF) and capillary density (Gjedde et al., 1990; Anderson et al., 1999; del Zoppo and Mabuchi, 2003), as well as major elevations in pro-angiogenic factors (Zhang and Chopp, 2002; Hayashi et al., 2003; Carmichael, 2006; Beck and Plate, 2009), the levels of which are predictive of functional outcome in stroke patients (Slevin et al., 2000; Sobrino et al., 2007). Angiogenic microenvironments also are supportive of neurogenesis (Ohab et al., 2006). However, new vessels tend to be transient and leaky (Yu et al., 2007; Hayward et al., 2011), and there is a variable degree of 
recovery of $\mathrm{CBF}$ and vessel densities in humans (Gjedde et al., 1990; Krupinski et al., 1994; Szpak et al., 1999) and rodent models (Marti et al., 2000; Biernaskie et al., 2001; Lin et al., 2008; Mostany et al., 2011). Because sufficient blood flow is essential for activitydependent neural remodeling, RT efficacy could depend on the success of vascular remodeling, and it might promote or accelerate it depending on its timing. For example, sensory stimulation starting 3 days after cortical ischemia promotes angiogenesis and CBF recovery (Whitaker et al., 2007).

Vascular and glial responses to injury and to behavioral experience are potentially major sources of variability in RT efficacy and its optimal timing. For example, time courses and magnitudes of astrocytic and vascular reactions to injury are altered with age (Gao et al., 2009; Brown and Thore, 2011; Popa-Wagner et al., 2011), injury severity (Kim and Jones, 2010) and diabetes (Prakash et al., 2013; Tennant and Brown, 2013). Neuroregeneration time courses and magnitudes also vary with age (Anderson et al., 1986), injury severity (Kim and Jones, 2010), injury modality (Napieralski et al., 1996; Phillips and Reeves, 2001; Voorhies and Jones, 2002; Jones et al., 2012) and other conditions (Hermann and Chopp, 2012). Thus, while there are many potential targets for treatment in stages of neurogliavascular remodeling after stroke, there is also much potential for variability in the optimal timing of these treatments.

\section{EARLIER CAN BE MUCH BETTER FOR REHABILITATIVE TREATMENTS}

Motor RT after stroke can drive structural and functional reorganization of the injured motor cortex of humans (Taub et al., 2003; Mark et al., 2006; Dong et al., 2007; Sterling et al., 2013) and other animals (Jones et al., 1999; Biernaskie and Corbett, 2001; Frost et al., 2003; Dancause et al., 2005). In animal models, training the paretic limb in skilled reaching after cortical infarcts (Figure 1) increases its movement representation area (CastroAlamancos and Borrel, 1995; Nudo et al., 1996) and synaptic densities (Adkins et al., 2008) in residual motor cortex of the injured hemisphere. Blocking the reorganization prevents the functional gains (Ramanathan et al., 2006). In the absence of RT, representations of the paretic limb are reduced, even well outside of infarct borders (Nudo et al., 1996).

Several studies support that RT is more effective if initiated earlier after stroke. RT beginning within 1 week of motor cortical infarcts in monkeys spares the paretic hand representation in motor cortex compared with controls (Nudo et al., 1996), but this effect is lost if training is delayed until 30 days post-infarct (Barbay et al., 2006). In rats, greater improvements in the paretic forelimb, and less compensatory reliance on the nonparetic limb, result from RT initiated within 5, vs. 14 or 30, days post-ischemia (Biernaskie et al., 2004). In humans, early (within 4 days poststroke) interventions are associated with reduced disability at
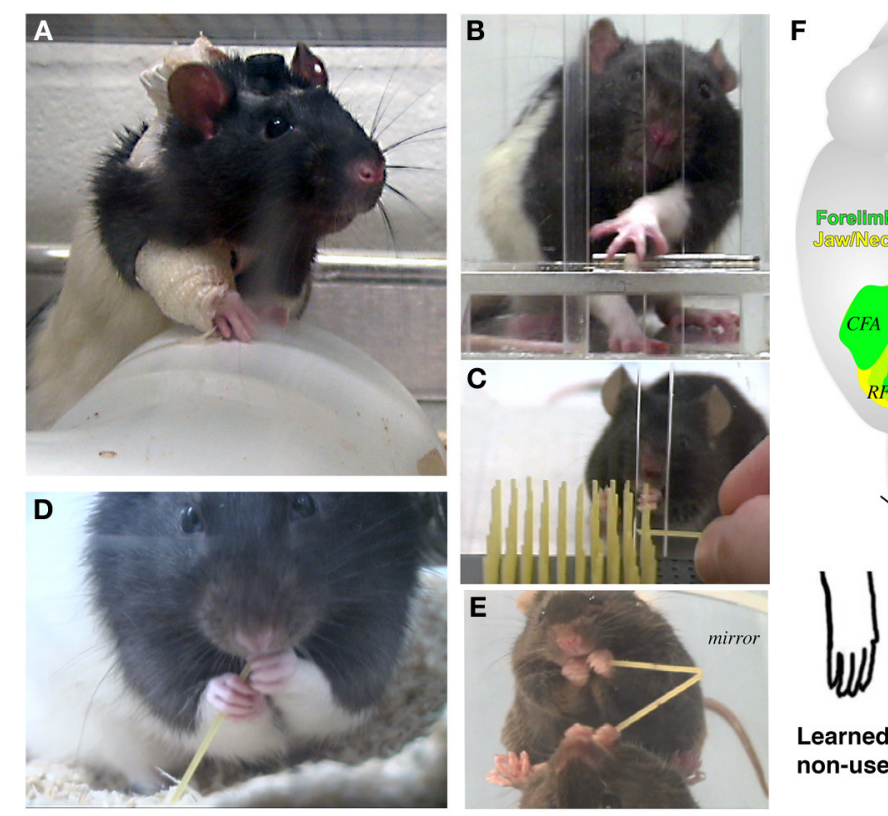

FIGURE 1 | Rodent models of upper extremity impairments after stroke used to study forelimb experience effects on brain and behavioral outcomes. Examples of behavioral manipulations in rats and mice include (A) forelimb constraint, used to force greater use of the paretic limb, (B,C) skilled reaching tasks, used to model both rehabilitative training (RT) focused on the paretic limb and compensatory skill learning with the nonparetic limb and, (D,E) pasta handling tasks, used to provide coordinated bimanual experience. (F) Approximate motor cortical infarct location (dark oval) used in several studies, as shown relative to head (yellow) and forelimb (green) movement representation regions of motor cortex. The caudal forelimb area (CFA) is in primary motor cortex and the rostral forelimb area (RFA) is in premotor/supplementary motor cortex. Motor cortical samples showing (G) vasculature (collagen IV immunolabeled), (H) a pyramidal neuron dendritic arbor (Golgi stained) and (I) synapses surrounded by peri-synaptic astrocytic processes (yellow highlights). The functional efficacy of motor RT has been linked with the reorganization of movement representations in peri-infarct motor cortex, but the influence of RT over time on the remodeling of surviving neurons, glia and vasculature has not yet been well examined. 
the time of hospital discharge compared with later interventions (Matsui et al., 2010). Patients receiving RT within 1 month poststroke have greater functional improvements and require shorter RT duration to achieve them compared to those with delayed RT (Salter et al., 2006). Constraint induced movement therapy (CIMT), initiated within 3-9 months post-stroke enhances performance in several fine motor tasks compared to delayed ( $>9$ months) CIMT (Lang et al., 2013).

In the studies above, RT timing was a categorical variable (earlier vs. later, Table 1), as is logical for determining if timing matters at all, but this does not lend precise information to the question of when, exactly, is optimal for RT onset. We also lack a precise understanding of the brain mechanisms of these time sensitivities. Our present understanding of RT mechanisms is based primarily on endpoint measures. We lack knowledge of how RT interacts with neuroremodeling responses as they unfold over time, and of the roles of vascular and glial plasticity in RT efficacy.

\section{EARLIER IS NOT BETTER FOR EVERYTHING}

Schallert and colleagues were the first to discover that forced use of a paretic limb, via constraint of the nonparetic limb, can be detrimental to functional outcome if done too early (Schallert et al., 2003). In rats, forelimb impairments are worsened, and injury size increased, by constraining the nonparetic limb for 2 weeks beginning immediately after motor cortical lesions (Kozlowski et al., 1996; see also Risedal et al., 1999;
Farrell et al., 2001). If constraint is delayed for 7 days, there is no detrimental effect (Humm et al., 1998). These constraint manipulations were dissimilar to the clinical application of CIMT, e.g., rats did not engage in RT and the constraint was continuous ( $24 \mathrm{~h} /$ day). In contrast, RT efficacy is improved by its combination with less intensive constraint ( $8 \mathrm{~h} /$ day) beginning 7 days after intracerbral hemorrhage in rats (DeBow et al., 2003). In humans, high intensity CIMT when initiated very early ( $\sim 10$ days) after stroke lessens functional improvement compared with lower intensity treatments (Dromerick et al., 2009).

Early intense exercise also can also be detrimental in rodent models of traumatic brain injury. Voluntary wheel running enhances cognitive performance if initiated after an acute (0-6 days) post-injury time period. However, exercise during the acute period impairs cognitive performance and prevents the normally seen up-regulation of BDNF (Griesbach et al., 2004, 2007; Griesbach, 2011).

Together, these findings support that highly intense physical activity very early after injury onset can be risky. We know of no evidence that less intense activity is detrimental. However, some types of RT might benefit from a delay, e.g., to allow resolution of metabolic dysfunction or target specific remodeling stages. Consistent with this possibility, intense cognitive training in rats is effective if it is initiated at 30 days, but not at 10 days, after hippocampal system lesions (Mala et al., 2012).

Table 1 | Time-sensitive effects of behavioral manipulations on functional outcome after brain damage in animal models.

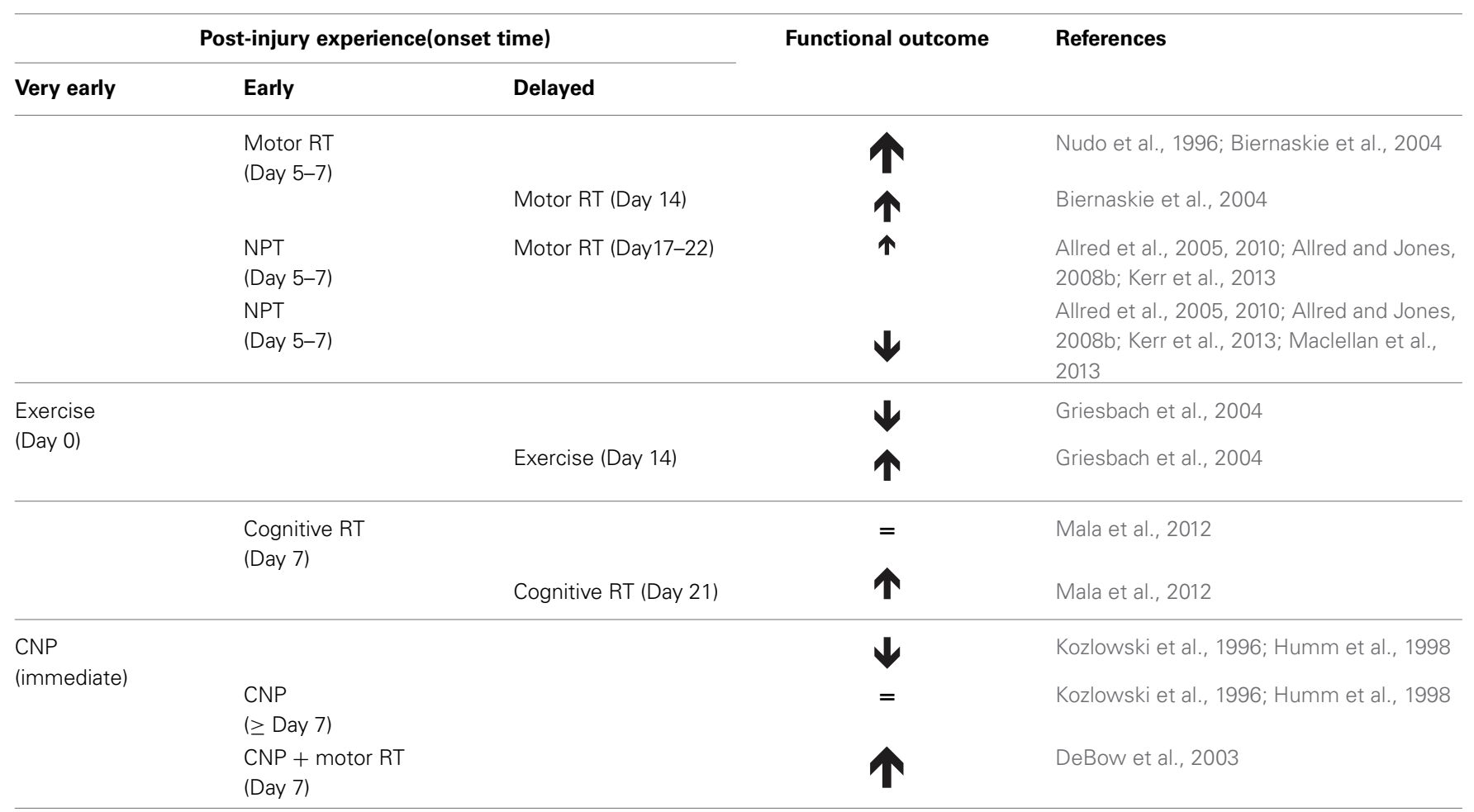

Onset time is relative to the time of injury. Behavioral manipulations continued for days to weeks after onset. Functional outcome direction is relative to no-behavioralmanipulation-controls with the same injury. RT, rehabilitative training; NPT, nonparetic limb training; CNP, constraint of the nonparetic limb. 


\section{TIMING-DEPENDENCIES-EFFECTS OF LEARNING TO COMPENSATE WITH THE NONPARETIC LIMB}

The typical response to upper extremity impairments is to learn to rely on the better functioning limb to perform daily activities. This compensatory strategy contributes to learned nonuse of the paretic side (Taub et al., 2006) and, because it begins early after stroke, it is also likely to interact with neural remodeling events. We've studied this in rodents with motor cortical infarcts, using training on reaching tasks to examine effects of skill learning with either forelimb (Jones et al., 2013). Skill training of the nonparetic forelimb (NPT) increases dendritic growth in the contralesional cortex, but this appears not to benefit the paretic limb (Jones and Jefferson, 2011). NPT also exacerbates disuse of the paretic forelimb, impairs the efficacy of subsequent paretic limb RT (Allred et al., 2005, 2010; Kerr et al., 2013) and reduces RTdriven neuronal activation of peri-lesion cortex (Allred and Jones, 2008a,b). Thus, NPT alters a neural substrate for RT efficacy. Maclellan et al. (2013) found that paretic limb function was worsened even when tested 30 days after an earlier period of NPT. Bilateral and unskilled limb use are not detrimental to paretic limb function, but learning new unimanual skills with the nonparetic limb is detrimental, at least after motor cortical infarcts (Allred and Jones, 2008a).

The influence of the nonparetic limb could vary with infarct territories. The disruptive effects of NPT depend on contralesional motor cortex and its transcallosal projections. They are blocked by callosal transections and absent after bilateral motor cortical lesions (Allred et al., 2010). Thus, injuries that leave little remaining territory for transcallosal projections are potentially immune from maladaptive effects of compensating with the nonparetic limb.

These findings suggest that experiences of the nonparetic body side may contribute to abnormal interhemispheric interactions after stroke (Murase et al., 2004; Calautti et al., 2010). They also indicate that RT efficacy can vary, not only with its timing after stroke, but also its timing relative to the development of compensatory skills with the nonparetic body side.

\section{CONCLUSIONS}

There are clearly early sensitive periods after stroke for the influence of RT and other behavioral experiences on functional outcome. It seems reasonable to assume that the early dynamic period of neural remodeling contribute to these time-sensitivities, but the remodeling process is complex and multiphasic, and the events or stages within it that are most important for RT efficacy have yet to be identified. For example, RT efficacy might benefit from coinciding with early stages of axonal sprouting, so that it shapes patterns of synaptic re-connectivity and effectively competes with maladaptive compensatory strategies in doing so. It could also depend on whether it is timed to coincide with stages of new vessel formation and/or stabilization, so that it can benefit from blood flow recovery or help promote it. These and other possibilities have yet to be directly tested, but it is feasible to do so in animal models of chronic stroke (Figure 1). It is also possible that, once events that contribute to heightened sensitivity to RT are identified, imaging or other assays could be used to reveal them in clinical populations. This could be essential to efforts to optimize RT, because the cellular conditions that create sensitive windows are likely to vary in time and magnitude with brain region, age, injuries and premorbid conditions. An "early" that is reliably best for RT in a reasonable portion of the clinical stroke population could be elusive in the realm of time, as measured by hours and days, but there is potential for it to be found within stages of sequential brain events. Knowledge of the events that create sensitive windows for experience-driven plasticity after stroke also could lead to treatments that promote these windows when they are deficient or reopen them after they have passed.

\section{ACKNOWLEDGMENTS}

The authors are grateful to the Bergeron Foundation for enabling experiences at the Georgetown University and National Rehabilitation Hospital Center for Brain Plasticity and Recovery that inspired the focus of this mini-review. We thank Drs. Kelly Tennant and Abigail Kerr for help with the figure. Supported by NINDS RO1 NS056839 and NS078791.

\section{REFERENCES}

Adkins, D. L., Boychuk, J., Remple, M. S., and Kleim, J. A. (2006). Motor training induces experience-specific patterns of plasticity across motor cortex and spinal cord. J. Appl. Physiol. 101, 1776-1782. doi: 10.1152/japplphysiol.005 15.2006

Adkins, D. L., Hsu, J. E., and Jones, T. A. (2008). Motor cortical stimulation promotes synaptic plasticity and behavioral improvements following sensorimotor cortex lesions. Exp. Neurol. 212, 14-28. doi: 10.1016/j.expneurol.2008.01.031

Allred, R. P., Cappellini, C. H., and Jones, T. A. (2010). The "good" limb makes the "bad" limb worse: experience-dependent interhemispheric disruption of functional outcome after cortical infarcts in rats. Behav. Neurosci. 124, 124-132. doi: 10.1037/a0018457

Allred, R. P., and Jones, T. A. (2008a). Experience-a double edged sword for restorative neural plasticity after brain damage. Future Neurol. 3, 189-198. doi: 10.2217/14796708.3.2.189

Allred, R. P., and Jones, T. A. (2008b). Maladaptive effects of learning with the lessaffected forelimb after focal cortical infarcts in rats. Exp. Neurol. 210, 172-181. doi: 10.1016/j.expneurol.2007.10.010

Allred, R. P., Maldonado, M. A., Hsu, J. E., and Jones, T. A. (2005). Training the "less-affected" forelimb after unilateral cortical infarcts interferes with functional recovery of the impaired forelimb in rats. Restor. Neurol. Neurosci. 23, 297-302.

Anderson, K. J., Scheff, S. W., and DeKosky, S. T. (1986). Reactive synaptogenesis in hippocampal area CA1 of aged and young adult rats. J. Comp. Neurol. 252, 374-384. doi: 10.1002/cne.902520306

Anderson, R. E., Tan, W. K., and Meyer, F. B. (1999). Brain acidosis, cerebral blood flow, capillary bed density, and mitochondrial function in the ischemic penumbra. J. Stroke Cerebrovasc. Dis. 8, 368-379. doi: 10.1016/S1052-3057(99)80044-5

Barbay, S., Plautz, E. J., Friel, K. M., Frost, S. B., Dancause, N., Stowe, A. M., et al. (2006). Behavioral and neurophysiological effects of delayed training following a small ischemic infarct in primary motor cortex of squirrel monkeys. Exp. Brain Res. 169, 106-116. doi: 10.1007/s00221-005-0129-4

Beck, H., and Plate, K. H. (2009). Angiogenesis after cerebral ischemia. Acta Neuropathol. 117, 481-496. doi: 10.1007/s00401-009-0483-6

Berardi, N., Pizzorusso, T., Ratto, G. M., and Maffei, L. (2003). Molecular basis of plasticity in the visual cortex. Trends Neurosci. 26, 369-378. doi: 10.1016/S01662236(03)00168-1

Bernhardt, J., Chan, J., Nicola, I., and Collier, J. M. (2007). Little therapy, little physical activity: rehabilitation within the first 14 days of organized stroke unit care. J. Rehabil. Med. 39, 43-48. doi: 10.2340/16501977-0013

Bernhardt, J., Dewey, H., Thrift, A., and Donnan, G. (2004). Inactive and alone: physical activity within the first 14 days of acute stroke unit care. Stroke 35, 1005-1009. doi: 10.1161/01.STR.0000120727.40792.40

Biernaskie, J., Chernenko, G., and Corbett, D. (2004). Efficacy of rehabilitative experience declines with time after focal ischemic brain injury. J. Neurosci. 24, 1245-1254. doi: 10.1523/JNEUROSCI.3834-03.2004 
Biernaskie, J., and Corbett, D. (2001). Enriched rehabilitative training promotes improved forelimb motor function and enhanced dendritic growth after focal ischemic injury. J. Neurosci. 21, 5272-5280.

Biernaskie, J., Corbett, D., Peeling, J., Wells, J., and Lei, H. (2001). A serial MR study of cerebral blood flow changes and lesion development following endothelin-1-induced ischemia in rats. Magn. Reson. Med. 46, 827-830. doi: 10.1002/mrm. 1263

Black, J. E., Jones, T. A., Nelson, C. A., and Greenough, W. T. (1997). "Chapter 2, Neuronal plasticity and the developing brain," in Handbook of Child and Adolescent Psychiatry, Vol. 6, Basic Psychiatric Treatment and Science, eds J. D. Noshpitz, N. E. Alessi, J. T. Coyle, and S. Eth (New York, NY: John Wiley and Sons), 31-53.

Brown, C. E., Boyd, J. D., and Murphy, T. H. (2010). Longitudinal in vivo imaging reveals balanced and branch-specific remodeling of mature cortical pyramidal dendritic arbors after stroke. J. Cereb. Blood Flow Metab. 30, 783-791. doi: 10.1038/jcbfm.2009.241

Brown, C. E., Wong, C., and Murphy, T. H. (2008). Rapid morphologic plasticity of peri-infarct dendritic spines after focal ischemic stroke. Stroke 39, 1286-1291. doi: 10.1161/STROKEAHA.107.498238

Brown, W. R., and Thore, C. R. (2011). Review: cerebral microvascular pathology in ageing and neurodegeneration. Neuropathol. Appl. Neurobiol. 37, 56-74. doi: 10.1111/j.1365-2990.2010.01139.x

Brus-Ramer, M., Carmel, J. B., Chakrabarty, S., and Martin, J. H. (2007). Electrical stimulation of spared corticospinal axons augments connections with ipsilateral spinal motor circuits after injury. J. Neurosci. 27, 13793-13801. doi: 10.1523/JNEUROSCI.3489-07.2007

Bury, S. D., Eichhorn, A. C., Kotzer, C. M., and Jones, T. A. (2000). Reactive astrocytic responses to denervation in the motor cortex of adult rats are sensitive to manipulations of behavioral experience. Neuropharmacology 39, 743-755. doi: 10.1016/S0028-3908(99)00272-5

Calautti, C., Jones, P. S., Naccarato, M., Sharma, N., Day, D. J., Bullmore, E. T., et al. (2010). The relationship between motor deficit and primary motor cortex hemispheric activation balance after stroke: longitudinal fMRI study. J. Neurol. Neurosurg. Psychiatry 81, 788-792. doi: 10.1136/jnnp.2009.190512

Carmel, J. B., Berrol, L. J., Brus-Ramer, M., and Martin, J. H. (2010). Chronic electrical stimulation of the intact corticospinal system after unilateral injury restores skilled locomotor control and promotes spinal axon outgrowth. J. Neurosci. 30, 10918-10926. doi: 10.1523/JNEUROSCI.143510.2010

Carmichael, S. T. (2003). Plasticity of cortical projections after stroke. Neuroscientist 9, 64-75. doi: 10.1177/1073858402239592

Carmichael, S. T. (2006). Cellular and molecular mechanisms of neural repair after stroke: making waves. Ann. Neurol. 59, 735-742. doi: 10.1002/ana.20845

Carmichael, S. T. (2012). Brain excitability in stroke: the yin and yang of stroke progression. Arch. Neuol. 69, 161-167. doi: 10.1001/archneurol.2011.1175

Carmichael, S. T., and Chesselet, M. F. (2002). Synchronous neuronal activity is a signal for axonal sprouting after cortical lesions in the adult. J. Neurosci. 22, 6062-6070.

Castro-Alamancos, M. A., and Borrel, J. (1995). Functional recovery of forelimb response capacity after forelimb primary motor cortex damage in the rat is due to the reorganization of adjacent areas of cortex. Neuroscience 68, 793-805. doi: 10.1016/0306-4522(95)00178-L

Cesa, R., and Strata, P. (2005). Axonal and synaptic remodeling in the mature cerebellar cortex. Prog. Brain Res. 148, 45-56. doi: 10.1016/S0079-6123(04)48005-4

Cheatwood, J. L., Emerick, A. J., and Kartje, G. L. (2008). Neuronal plasticity and functional recovery after ischemic stroke. Top. Stroke Rehabil. 15, 42-50. doi: 10.1310/tsr1501-42

Christopherson, K. S., Ullian, E. M., Stokes, C. C., Mullowney, C. E., Hell, J. W., Agah, A., et al. (2005). Thrombospondins are astrocyte-secreted proteins that promote CNS synaptogenesis. Cell 120, 421-433. doi: 10.1016/j.cell.2004. 12.020

Cotman, C. W., and Anderson, K. J. (1988). Synaptic plasticity and functional stabilization in the hippocampal formation: possible role in Alzheimer's disease. Adv. Neurol. 47, 313-335.

Cramer, S. C., and Chopp, M. (2000). Recovery recapitulates ontogeny. Trends Neurosci. 23, 265-271. doi: 10.1016/S0166-2236(00)01562-9

Dancause, N., Barbay, S., Frost, S. B., Plautz, E. J., Chen, D., Zoubina, E. V., et al. (2005). Extensive cortical rewiring after brain injury. J. Neurosci. 25, 10167-10179. doi: 10.1523/JNEUROSCI.3256-05.2005
Dayan, E., and Cohen, L. G. (2011). Neuroplasticity subserving motor skill learning. Neuron 72, 443-454. doi: 10.1016/j.neuron.2011.10.008

DeBow, S. B., Davies, M. L., Clarke, H. L., and Colbourne, F. (2003). Constraintinduced movement therapy and rehabilitation exercises lessen motor deficits and volume of brain injury after striatal hemorrhagic stroke in rats. Stroke 34, 1021-1026. doi: 10.1161/01.STR.0000063374.89732.9F

del Zoppo, G. J., and Mabuchi, T. (2003). Cerebral microvessel responses to focal ischemia. J. Cereb. Blood Flow Metab. 23, 879-894. doi: 10.1097/01.WCB.0000078322.96027.78

Dong, Y., Winstein, C. J., Albistegui-DuBois, R., and Dobkin, B. H. (2007). Evolution of FMRI activation in the perilesional primary motor cortex and cerebellum with rehabilitation training-related motor gains after stroke: a pilot study. Neurorehabil. Neural Repair 21, 412-428. doi: $10.1177 / 1545968306298598$

Dromerick, A. W., Lang, C. E., Birkenmeier, R. L., Wagner, J. M., Miller, J. P., Videen, T. O., et al. (2009). Very early constraint-induced movement during stroke rehabilitation (VECTORS): a single-center RCT. Neurology 73, 195-201. doi: 10.1212/WNL.0b013e3181ab2b27

Eroglu, C., Allen, N. J., Susman, M. W., O’Rourke, N. A., Park, C. Y., Ozkan, E., et al. (2009). Gabapentin receptor alpha2delta-1 is a neuronal thrombospondin receptor responsible for excitatory CNS synaptogenesis. Cell 139, 380-392. doi: 10.1016/j.cell.2009.09.025

Eroglu, C., and Barres, B. A. (2010). Regulation of synaptic connectivity by glia. Nature 468, 223-231. doi: 10.1038/nature09612

Farrell, R., Evans, S., and Corbett, D. (2001). Environmental enrichment enhances recovery of function but exacerbates ischemic cell death. Neuroscience 107, 585-592. doi: 10.1016/S0306-4522(01)00386-4

Frost, S. B., Barbay, S., Friel, K. M., Plautz, E. J., and Nudo, R. J. (2003). Reorganization of remote cortical regions after ischemic brain injury: a potential substrate for stroke recovery. J. Neurophysiol 89, 3205-3214. doi: 10.1152/jn.01143.2002

Gao, P., Shen, F., Gabriel, R. A., Law, D., Yang, E., Yang, G. Y., et al. (2009). Attenuation of brain response to vascular endothelial growth factor-mediated angiogenesis and neurogenesis in aged mice. Stroke 40, 3596-3600. doi: 10.1161/STROKEAHA.109.561050

Gjedde, A., Kuwabara, H., and Hakim, A. M. (1990). Reduction of functional capillary density in human brain after stroke. J. Cereb. Blood Flow Metab. 10, 317-326. doi: 10.1038/jcbfm. 1990.60

Goritz, C., Mauch, D. H., and Pfrieger, F. W. (2005). Multiple mechanisms mediate cholesterol-induced synaptogenesis in a CNS neuron. Mol. Cell. Neurosci. 29, 190-201. doi: 10.1016/j.mcn.2005.02.006

Greenough, W. T., Black, J. E., and Wallace, C. S. (1987). Experience and brain development. Child Dev. 58, 539-559. doi: 10.2307/1130197

Griesbach, G. S. (2011). Exercise after traumatic brain injury: is it a double-edged sword? PM R 3, S64-S72. doi: 10.1016/j.pmrj.2011.02.008

Griesbach, G. S., Gomez-Pinilla, F., and Hovda, D. A. (2007). Time window for voluntary exercise-induced increases in hippocampal neuroplasticity molecules after traumatic brain injury is severity dependent. J. Neurotrauma 24, 1161-1171. doi: 10.1089/neu.2006.0255

Griesbach, G. S., Hovda, D. A., Molteni, R., Wu, A., and Gomez-Pinilla, F. (2004). Voluntary exercise following traumatic brain injury: brain-derived neurotrophic factor upregulation and recovery of function. Neuroscience 125, 129-139. doi: 10.1016/j.neuroscience.2004.01.030

Haber, M., Zhou, L., and Murai, K. K. (2006). Cooperative astrocyte and dendritic spine dynamics at hippocampal excitatory synapses. J. Neurosci. 26, 8881-8891. doi: 10.1523/JNEUROSCI.1302-06.2006

Hayashi, T., Noshita, N., Sugawara, T., and Chan, P. H. (2003). Temporal profile of angiogenesis and expression of related genes in the brain after ischemia. J. Cereb. Blood Flow Metab. 23, 166-180. doi: 10.1097/00004647-200302000-00004

Hayward, N. M., Yanev, P., Haapasalo, A., Miettinen, R., Hiltunen, M., Grohn, O., et al. (2011). Chronic hyperperfusion and angiogenesis follow subacute hypoperfusion in the thalamus of rats with focal cerebral ischemia. J. Cereb. Blood Flow Metab. 31, 1119-1132. doi: 10.1038/jcbfm.2010.202

Hermann, D. M., and Chopp, M. (2012). Promoting brain remodelling and plasticity for stroke recovery: therapeutic promise and potential pitfalls of clinical translation. Lancet Neurol. 11, 369-380. doi: 10.1016/S1474-4422(12)70039-X

Hsu, J. E., and Jones, T. A. (2006). Contralesional neural plasticity and functional changes in the less-affected forelimb after large and small cortical infarcts in rats. Exp. Neurol. 201, 479-494. doi: 10.1016/j.expneurol.2006.05.003 
Hubel, D. H., and Wiesel, T. N. (1965). Binocular interaction in striate cortex of kittens reared with artificial squint. J. Neurophysiol. 28, 1041-1059.

Humm, J. L., Kozlowski, D. A., James, D. C., Gotts, J. E., and Schallert, T. (1998). Use-dependent exacerbation of brain damage occurs during an early postlesion vulnerable period. Brain Res. 783, 286-292. doi: 10.1016/S0006-8993(97) 01356-5

Johnston, S. C., Mendis, S., and Mathers, C. D. (2009). Global variation in stroke burden and mortality: estimates from monitoring, surveillance, and modelling. Lancet Neurol. 8, 345-354. doi: 10.1016/S1474-4422(09)70023-7

Jones, T. A., and Adkins, D. L. (2010). "Behavioral influences on neuronal events after stroke," in Brain Repair after Stroke, eds S. C. Cramer and R. J. Nudo (Cambridge: Cambridge University Press), 23-34. doi: 10.1017/CBO9780511777547.004

Jones, T. A., Allred, R. P., Jefferson, S. C., Kerr, A. L., Woodie, D. A., Cheng, S. Y., et al. (2013). Motor system plasticity in stroke models: intrinsically use-dependent, unreliably useful. Stroke 44, S104-106. doi: 10.1161/STROKEAHA.111.000037

Jones, T. A., Chu, C. J., Grande, L. A., and Gregory, A. D. (1999). Motor skills training enhances lesion-induced structural plasticity in the motor cortex of adult rats. J. Neurosci. 19, 10153-10163.

Jones, T. A., and Greenough, W. T. (2002). "Chapter 19, Behavioral experiencedependent plasticity of glial-neuronal interactions," in Glia in Synaptic Transmission, eds A. Volterra, P. Magistretti, and P. G. Haydon (Oxford: Oxford University Press), 248-265.

Jones, T. A., Hawrylak, N., Klintsova, A. Y., and Greenough, W. T. (1998). Brain damage, behavior, rehabilitation, recovery, and brain plasticity. Ment. Retard. Dev. D. R. 4, 231-237.

Jones, T. A., and Jefferson, S. C. (2011). Reflections of experience-expectant development in repair of the adult damaged brain. Dev. Psychobiol. 53, 466-475. doi: 10.1002/dev.20557

Jones, T. A., Liput, D. J., Maresh, E. L., Donlan, N., Parikh, T. J., Marlowe, D., et al. (2012). Use-dependent dendritic regrowth is limited after unilateral controlled cortical impact to the forelimb sensorimotor cortex. J. Neurotrauma 29, 1455-1468. doi: 10.1089/neu.2011.2207

Kelley, M. S., and Steward, O. (1997). Injury-induced physiological events that may modulate gene expression in neurons and glia. Rev. Neurosci. 8, 147-177. doi: 10.1515/REVNEURO.1997.8.3-4.147

Kerr, A. L., Cheng, S.-Y., and Jones, T. A. (2011). Experience-dependent neural plasticity in the adult damaged brain. J. Commun. Disord. 44, 538-548. doi: 10.1016/j.jcomdis.2011.04.011

Kerr, A. L., Wolke, M. L., Bell, J. A., and Jones, T. A. (2013). Post-stroke protection from maladaptive effects of learning with the non-paretic forelimb by bimanual home cage experience in C57BL/6 mice. Behav. Brain Res. 252, 180-187. doi: 10.1016/j.bbr.2013.05.062

Kim, S. Y., and Jones, T. A. (2010). Lesion size-dependent synaptic and astrocytic responses in cortex contralateral to infarcts in middle-aged rats. Synapse 64, 659-671. doi: 10.1002/syn.20777

Kim, S. Y., and Jones, T. A. (2013). The effects of ceftriaxone on skill learning and motor functional outcome after ischemic cortical damage in rats. Restor. Neurol. Neurosci. 31, 87-97. doi: 10.3233/RNN-2012-120245

Kleim, J. A., Chan, S., Pringle, E., Schallert, K., Procaccio, V., Jimenez, R., et al. (2006). BDNF val66met polymorphism is associated with modified experiencedependent plasticity in human motor cortex. Nat. Neurosci. 9, 735-737. doi: 10.1038/nn1699

Kozlowski, D. A., James, D. C., and Schallert, T. (1996). Use-dependent exaggeration of neuronal injury after unilateral sensorimotor cortex lesions. J. Neurosci. $16,4776-4786$.

Krakauer, J. W. (2007). The complex dynamics of stroke onset and progression. Curr. Opin. Neurol. 20, 47-50. doi: 10.1097/WCO.0b013e328013f86b

Krupinski, J., Kaluza, J., Kumar, P., Kumar, S., and Wang, J. M. (1994). Role of angiogenesis in patients with cerebral ischemic stroke. Stroke 25, 1794-1798. doi: 10.1161/01.STR.25.9.1794

Kwakkel, G., Kollen, B. J., van der Grond, J., and Prevo, A. J. (2003). Probability of regaining dexterity in the flaccid upper limb: impact of severity of paresis and time since onset in acute stroke. Stroke 34, 2181-2186. doi: 10.1161/01.STR.0000087172.16305.CD

Lai, S. M., Studenski, S., Duncan, P. W., and Perera, S. (2002). Persisting consequences of stroke measured by the Stroke Impact Scale. Stroke 33, 1840-1844. doi: 10.1161/01.STR.0000019289.15440.F2
Lang, K. C., Thompson, P. A., and Wolf, S. L. (2013). The EXCITE Trial: reacquiring upper-extremity task performance with early versus late delivery of constraint therapy. Neurorehabil. Neural Repair 27, 654-663. doi: $10.1177 / 1545968313481281$

Li, S., and Carmichael, S. T. (2006). Growth-associated gene and protein expression in the region of axonal sprouting in the aged brain after stroke. Neurobiol. Dis. 23, 362-373. doi: 10.1016/j.nbd.2006.03.011

Lin, C. Y., Chang, C., Cheung, W. M., Lin, M. H., Chen, J. J., Hsu, C. Y., et al. (2008). Dynamic changes in vascular permeability, cerebral blood volume, vascular density, and size after transient focal cerebral ischemia in rats: evaluation with contrast-enhanced magnetic resonance imaging. J. Cereb. Blood Flow Metab. 28, 1491-1501. doi: 10.1038/jcbfm.2008.42

Mack, A. F., and Wolburg, H. (2013). A novel look at astrocytes: aquaporins, ionic homeostasis, and the role of the microenvironment for regeneration in the CNS. Neuroscientist 19, 195-207. doi: 10.1177/1073858412447981

Maclellan, C. L., Langdon, K. D., Botsford, A., Butt, S., and Corbett, D. (2013). A Model of Persistent Learned Nonuse Following Focal Ischemia in Rats. Neurorehabil. Neural Repair 27, 900-907. doi: 10.1177/15459683134 96323

Mala, H., Rodriguez Castro, M., Pearce, H., Kingod, S. C., Nedergaard, S. K., Scharff, Z., et al. (2012). Delayed intensive acquisition training alleviates the lesion-induced place learning deficits after fimbria-fornix transection in the rat. Brain Res. 1445, 40-51. doi: 10.1016/j.brainres.2012.01.035

Mark, V. W., Taub, E., and Morris, D. M. (2006). Neuroplasticity and constraintinduced movement therapy. Eura. Medicophys. 42, 269-284.

Marti, H. J., Bernaudin, M., Bellail, A., Schoch, H., Euler, M., Petit, E., et al. (2000). Hypoxia-induced vascular endothelial growth factor expression precedes neovascularization after cerebral ischemia. Am. J. Pathol. 156, 965-976. doi: $10.1016 / \mathrm{S} 0002-9440(10) 64964-4$

Matsui, H., Hashimoto, H., Horiguchi, H., Yasunaga, H., and Matsuda, S. (2010). An exploration of the association between very early rehabilitation and outcome for the patients with acute ischaemic stroke in Japan: a nationwide retrospective cohort survey. BMC Health Serv. Res. 10:213. doi: 10.1186/1472-6963$10-213$

Mauch, D. H., Nagler, K., Schumacher, S., Goritz, C., Muller, E. C., Otto, A., et al. (2001). CNS synaptogenesis promoted by glia-derived cholesterol. Science 294, 1354-1357. doi: 10.1126/science.294.5545.1354

McNeill, T. H., Brown, S. A., Hogg, E., Cheng, H. W., and Meshul, C. K. (2003). Synapse replacement in the striatum of the adult rat following unilateral cortex ablation. J. Comp. Neurol. 467, 32-43. doi: 10.1002/cne.10907

Monfils, M. H., Plautz, E. J., and Kleim, J. A. (2005). In search of the motor engram: motor map plasticity as a mechanism for encoding motor experience. Neuroscientist 11, 471-483. doi: 10.1177/1073858405278015

Morishita, H., and Hensch, T. K. (2008). Critical period revisited: impact on vision. Curr. Opin. Neurobiol. 18, 101-107. doi: 10.1016/j.conb.2008.05.009

Mostany, R., Chowdhury, T. G., Johnston, D. G., Portonovo, S. A., Carmichael, S. T., and Portera-Cailliau, C. (2011). Local hemodynamics dictate long-term dendritic plasticity in peri-infarct cortex. J. Neurosci. 30, 14116-14126. doi: 10.1523/JNEUROSCI.3908-10.2010

Murai, K. K., Nguyen, L. N., Irie, F., Yamaguchi, Y., and Pasquale, E. B. (2003). Control of hippocampal dendritic spine morphology through ephrinA3/EphA4 signaling. Nat. Neurosci. 6, 153-160. doi: 10.1038/nn994

Murase, N., Duque, J., Mazzocchio, R., and Cohen, L. G. (2004). Influence of interhemispheric interactions on motor function in chronic stroke. Ann. Neurol. 55, 400-409. doi: 10.1002/ana.10848

Murphy, T. H., and Corbett, D. (2009). Plasticity during stroke recovery: from synapse to behaviour. Nat. Rev. Neurosci. 10, 861-872. doi: 10.1038/nrn2735

Napieralski, J. A., Butler, A. K., and Chesselet, M. F. (1996). Anatomical and functional evidence for lesion-specific sprouting of corticostriatal input in the adult rat. J. Comp. Neurol. 373, 484-497.

Nudo, R. J. (2003). Adaptive plasticity in motor cortex: implications for rehabilitation after brain injury. J. Rehabil. Med. 41, 7-10. doi: $10.1080 / 16501960310010070$

Nudo, R. J., Wise, B. M., SiFuentes, F., and Milliken, G. W. (1996). Neural substrates for the effects of rehabilitative training on motor recovery after ischemic infarct. Science 272, 1791-1794. doi: 10.1126/science.272.5269.1791

Ohab, J. J., Fleming, S., Blesch, A., and Carmichael, S. T. (2006). A neurovascular niche for neurogenesis after stroke. J. Neurosci. 26, 13007-130016. doi: 10.1523/JNEUROSCI.4323-06.2006 
Overman, W. T., Eckstein, I., Maguire, J. L., Dinov, I. D., Toga, A. W., and Carmichael, S. T. (2012). A role for ephrin-A5 in axonal sprouting, recovery, and activity-dependent plasticity after stroke. Proc. Natl. Acad. Sci. U.S.A. 109, E2230-E2239. doi: 10.1073/pnas.1204386109

Panatier, A., Theodosis, D. T., Mothet, J. P., Touquet, B., Pollegioni, L., Poulain, D. A., et al. (2006). Glia-derived D-serine controls NMDA receptor activity and synaptic memory. Cell 125, 775-784. doi: 10.1016/j.cell.2006.02.051

Phillips, L. L., and Reeves, T. M. (2001). Interactive pathology following traumatic brain injury modifies hippocampal plasticity. Restor. Neurol. Neurosci. 19, 213-235.

Popa-Wagner, A., Buga, A. M., and Kokaia, Z. (2011). Perturbed cellular response to brain injury during aging. Ageing Res. Rev. 10, 71-79. doi: 10.1016/j.arr.2009.10.008

Prakash, R., Li, W., Qu, Z., Johnson, M. A., Fagan, S. C., and Ergul, A. (2013). Vascularization pattern after ischemic stroke is different in control versus diabetic rats: relevance to stroke recovery. Stroke 44, 2875-2882. doi: 10.1161/STROKEAHA.113.001660

Raisman, G., and Field, P. M. (1990). Synapse formation in the adult brain after lesions and after transplantation of embryonic tissue. J. Exp. Biol. 153, 277-287.

Ramanathan, D., Conner, J. M., and Tuszynski, M. H. (2006). A form of motor cortical plasticity that correlates with recovery of function after brain injury. Proc. Natl. Acad. Sci. U.S.A. 103, 11370-11375. doi: 10.1073/pnas.0601065103

Riley, J. D., Le, V., Der-Yeghiaian, L., See, J., Newton, J. M., Ward, N. S., et al. (2011). Anatomy of stroke injury predicts gains from therapy. Stroke 42, 421-426. doi: 10.1161/STROKEAHA.110.599340

Risedal, A., Zeng, J., and Johansson, B. B. (1999). Early training may exacerbate brain damage after focal brain ischemia in the rat. J. Cereb. Blood Flow Metab. 19, 997-1003. doi: 10.1097/00004647-199909000-00007

Salter, K., Jutai, J., Hartley, M., Foley, N., Bhogal, S., Bayona, N., et al. (2006). Impact of early vs delayed admission to rehabilitation on functional outcomes in persons with stroke. J. Rehabil. Med. 38, 113-117. doi: $10.1080 / 16501970500314350$

Schallert, T., Fleming, S. M., and Woodlee, M. T. (2003). Should the injured and intact hemispheres be treated differently during the early phases of physical restorative therapy in experimental stroke or parkinsonism? Phys. Med. Rehabil. Clin. N. Am. 14, S27-S46. doi: 10.1016/S1047-9651(02)00055-4

Sigler, A., and Murphy, T. H. (2010). In vivo 2-photon imaging of fine structure in the rodent brain: before, during, and after stroke. Stroke 41, S117-S123. doi: 10.1161/STROKEAHA.110.594648

Slevin, M., Krupinski, J., Slowik, A., Kumar, P., Szczudlik, A., and Gaffney, J. (2000). Serial measurement of vascular endothelial growth factor and transforming growth factor-betal in serum of patients with acute ischemic stroke. Stroke 31, 1863-1870. doi: 10.1161/01.STR.31.8.1863

Sobrino, T., Hurtado, O., Moro, M. A., Rodriguez-Yanez, M., Castellanos, M., Brea, D., et al. (2007). The increase of circulating endothelial progenitor cells after acute ischemic stroke is associated with good outcome. Stroke 38, 2759-2764. doi: 10.1161/STROKEAHA.107.484386

Sterling, C., Taub, E., Davis, D., Rickards, T., Gauthier, L. V., Griffin, A., et al. (2013). Structural neuroplastic change after constraint-induced movement therapy in children with cerebral palsy. Pediatrics 131, e1664-e1669. doi: 10.1542/peds.2012-2051

Szpak, G. M., Lechowicz, W., Lewandowska, E., Bertrand, E., Wierzba-Bobrowicz, T., and Dymecki, J. (1999). Border zone neovascularization in cerebral ischemic infarct. Folia Neuropathol. 37, 264-268.

Taub, E., Uswatte, G., Mark, V. W., and Morris, D. M. (2006). The learned nonuse phenomenon: implications for rehabilitation. Eura. Medicophys. 42, 241-256.

Taub, E., Uswatte, G., and Morris, D. M. (2003). Improved motor recovery after stroke and massive cortical reorganization following Constraint-Induced Movement therapy. Phys. Med. Rehabil. Clin. N. Am. 14(1 Suppl), S77-S91, ix. doi: 10.1016/S1047-9651(02)00052-9
Tennant, K. A., and Brown, C. E. (2013). Diabetes augments in vivo microvascular blood flow dynamics after stroke. J. Neurosci. 33, 19194-19204. doi: 10.1523/JNEUROSCI.3513-13.2013

Theodosis, D. T., Poulain, D. A., and Oliet, S. H. (2008). Activity-dependent structural and functional plasticity of astrocyte-neuron interactions. Physiol. Rev. 88, 983-1008. doi: 10.1152/physrev.00036.2007

Voorhies, A. C., and Jones, T. A. (2002). The behavioral and dendritic growth effects of focal sensorimotor cortical damage depend on the method of lesion induction. Behav. Brain Res. 133, 237-246. doi: 10.1016/S0166-4328(02)00029-3

West, T., and Bernhardt, J. (2013). Physical activity patterns of acute stroke patients managed in a rehabilitation focused stroke unit. BioMed. Res. Int. 2013:438679. doi: 10.1155/2013/438679

Whitaker, V. R., Cui, L., Miller, S., Yu, S. P., and Wei, L. (2007). Whisker stimulation enhances angiogenesis in the barrel cortex following focal ischemia in mice. J. Cereb. Blood Flow Metab. 27, 57-68. doi: 10.1038/sj.jcbfm.9600318

Wieloch, T., and Nikolich, K. (2006). Mechanisms of neural plasticity following brain injury. Curr. Opin. Neurobiol. 16, 258-264. doi: 10.1016/j.conb.2006.05.011

Williams, P. T., Gharbawie, O. A., Kolb, B., and Kleim, J. A. (2006). Experiencedependent amelioration of motor impairments in adulthood following neonatal medial frontal cortex injury in rats is accompanied by motor map expansion. Neuroscience 141, 1315-1326. doi: 10.1016/j.neuroscience.2006.04.081

Wright, J. J., and Bourke, P. D. (2013). On the dynamics of cortical development: synchrony and synaptic self-organization. Front. Comput. Neurosci. 7:4. doi: 10.3389/fncom.2013.00004

Xu, T., Yu, X., Perlik, A. J., Tobin, W. F., Zweig, J. A., Tennant, K., et al. (2009). Rapid formation and selective stabilization of synapses for enduring motor memories. Nature 462, 915-919. doi: 10.1038/nature08389

Yu, S. W., Friedman, B., Cheng, Q., and Lyden, P. D. (2007). Stroke-evoked angiogenesis results in a transient population of microvessels. J. Cereb. Blood Flow Metab. 27, 755-763. doi: 10.1038/sj.jcbfm.9600378

Yu, X., Wang, G., Gilmore, A., Yee, A. X., Li, X., Xu, T., et al. (2013). Accelerated experience-dependent pruning of cortical synapses in ephrin-A2 knockout mice. Neuron 80, 64-71. doi: 10.1016/j.neuron.2013.07.014

Zeiler, S. R., Gibson, E. M., Hoesch, R. E., Li, M. Y., Worley, P. F., O’Brien, R. J., et al. (2013). Medial premotor cortex shows a reduction in inhibitory markers and mediates recovery in a mouse model of focal stroke. Stroke 44, 483-489. doi: 10.1161/STROKEAHA.112.676940

Zhang, Z., and Chopp, M. (2002). Vascular endothelial growth factor and angiopoietins in focal cerebral ischemia. Trends Cardiovasc. Med. 12, 62-66. doi: 10.1016/S1050-1738(01)00149-9

Zuo, Y., Lin, A., Chang, P., and Gan, W. B. (2005). Development of long-term dendritic spine stability in diverse regions of cerebral cortex. Neuron 46, 181-189. doi: 10.1016/j.neuron.2005.04.001

Conflict of Interest Statement: The authors declare that the research was conducted in the absence of any commercial or financial relationships that could be construed as a potential conflict of interest.

Received: 08 November 2013; accepted: 14 May 2014; published online: 27 June 2014. Citation: Allred RP, Kim SY and Jones TA (2014) Use it and/or lose it-experience effects on brain remodeling across time after stroke. Front. Hum. Neurosci. 8:379. doi: 10.3389/fnhum.2014.00379

This article was submitted to the journal Frontiers in Human Neuroscience.

Copyright (c) 2014 Allred, Kim and Jones. This is an open-access article distributed under the terms of the Creative Commons Attribution License (CC BY). The use, distribution or reproduction in other forums is permitted, provided the original author(s) or licensor are credited and that the original publication in this journal is cited, in accordance with accepted academic practice. No use, distribution or reproduction is permitted which does not comply with these terms. 